NASA/TM-2014-218493

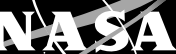

NASA Numerical and Experimental Evaluation of UTRC Low Emissions Injector

Yolanda R. Hicks, Sarah A. Tedder, Robert C. Anderson, and Anthony C. Iannetti Glenn Research Center, Cleveland, Ohio

Lance L. Smith and Zhongtao Dai

United Technologies Research Center, East Hartford, Connecticut 


\section{NASA STI Program . . . in Profile}

Since its founding, NASA has been dedicated to the advancement of aeronautics and space science. The NASA Scientific and Technical Information (STI) program plays a key part in helping NASA maintain this important role.

The NASA STI Program operates under the auspices of the Agency Chief Information Officer. It collects, organizes, provides for archiving, and disseminates NASA's STI. The NASA STI program provides access to the NASA Aeronautics and Space Database and its public interface, the NASA Technical Reports Server, thus providing one of the largest collections of aeronautical and space science STI in the world. Results are published in both non-NASA channels and by NASA in the NASA STI Report Series, which includes the following report types:

- TECHNICAL PUBLICATION. Reports of completed research or a major significant phase of research that present the results of NASA programs and include extensive data or theoretical analysis. Includes compilations of significant scientific and technical data and information deemed to be of continuing reference value. NASA counterpart of peer-reviewed formal professional papers but has less stringent limitations on manuscript length and extent of graphic presentations.

- TECHNICAL MEMORANDUM. Scientific and technical findings that are preliminary or of specialized interest, e.g., quick release reports, working papers, and bibliographies that contain minimal annotation. Does not contain extensive analysis.

- CONTRACTOR REPORT. Scientific and technical findings by NASA-sponsored contractors and grantees.
- CONFERENCE PUBLICATION. Collected papers from scientific and technical conferences, symposia, seminars, or other meetings sponsored or cosponsored by NASA.

- SPECIAL PUBLICATION. Scientific, technical, or historical information from NASA programs, projects, and missions, often concerned with subjects having substantial public interest.

- TECHNICAL TRANSLATION. Englishlanguage translations of foreign scientific and technical material pertinent to NASA's mission.

Specialized services also include creating custom thesauri, building customized databases, organizing and publishing research results.

For more information about the NASA STI program, see the following:

- Access the NASA STI program home page at http://www.sti.nasa.gov

- E-mail your question to help@sti.nasa.gov

- Fax your question to the NASA STI Information Desk at 443-757-5803

- Phone the NASA STI Information Desk at 443-757-5802

- Write to: STI Information Desk NASA Center for AeroSpace Information 7115 Standard Drive Hanover, MD 21076-1320 
NASA/TM-2014-218493

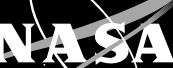

NASA Numerical and Experimental Evaluation of UTRC Low Emissions Injector

Yolanda R. Hicks, Sarah A. Tedder, Robert C. Anderson, and Anthony C. Iannetti Glenn Research Center, Cleveland, Ohio

Lance L. Smith and Zhongtao Dai

United Technologies Research Center, East Hartford, Connecticut

Prepared for the

50th Joint Propulsion Conference

cosponsored by the AIAA, ASME, SAE, and ASEE

Cleveland, Ohio, July 28-30, 2014

National Aeronautics and

Space Administration

Glenn Research Center

Cleveland, Ohio 44135 


\section{Acknowledgments}

This work was supported by the Supersonics Project of the NASA Fundamental Aeronautics Program and by the NASA Environmentally Responsible Aviation Program. We also thank Changlie Wey and Randy Locke for their assistance in conducting the experiments.

This report is a formal draft or working paper, intended to solicit comments and ideas from a technical peer group.

Trade names and trademarks are used in this report for identification only. Their usage does not constitute an official endorsement, either expressed or implied, by the National Aeronautics and Space Administration.

Level of Review: This material has been technically reviewed by technical management.

Available from

NASA Center for Aerospace Information 7115 Standard Drive

Hanover, MD 21076-1320
National Technical Information Service 5301 Shawnee Road Alexandria, VA 22312

Available electronically at http://www.sti.nasa.gov 


\title{
NASA Numerical and Experimental Evaluation of UTRC Low Emissions Injector
}

\author{
Yolanda R. Hicks, Sarah A. Tedder, Robert C. Anderson, and Anthony C. Iannetti \\ National Aeronautics and Space Administration \\ Glenn Research Center \\ Cleveland, Ohio 44135
}

Lance L. Smith and Zhongtao Dai

United Technologies Research Center

East Hartford, Connecticut 06108

\begin{abstract}
Computational and experimental analyses of a PICS - Pilot-In-Can-Swirler technology injector, developed by United Technologies Research Center (UTRC) are presented. NASA has defined technology targets for near term (called "N+1", circa 2015), midterm ("N+2", circa 2020) and far term ("N+3", circa 2030) that specify realistic emissions and fuel efficiency goals for commercial aircraft. This injector has potential for application in an engine to meet the Pratt \& Whitney N+3 supersonic cycle goals, or the subsonic N+2 engine cycle goals. Experimental methods were employed to investigate supersonic cruise points as well as select points of the subsonic cycle engine; cruise, approach, and idle with a slightly elevated inlet pressure.

Experiments at NASA employed gas analysis and a suite of laser-based measurement techniques to characterize the combustor flow downstream from the PICS dump plane. Optical diagnostics employed for this work included Planar Laser-Induced Fluorescence of fuel for injector spray pattern and Spontaneous Raman Spectroscopy for relative species concentration of fuel and $\mathrm{CO}_{2}$.

The work reported here used unheated (liquid) Jet-A fuel for all fuel circuits and cycle conditions. The initial tests performed by UTRC used vaporized Jet-A to simulate the expected supersonic cruise condition, which anticipated using fuel as a heat sink.

Using the National Combustion Code a PICS-based combustor was modeled with liquid fuel at the supersonic cruise condition. All CFD models used a cubic non-linear k-epsilon turbulence wall functions model, and a semi-detailed Jet-A kinetic mechanism based on a surrogate fuel mixture. Two initial spray droplet size distribution and spray cone conditions were used: (1) an initial condition (Lefebvre) with an assumed Rosin-Rammler distribution, and 7 degree Solid Spray Cone; and (2) the Boundary Layer Stripping (BLS) primary atomization model giving the spray size distribution and directional properties. Contour and line plots are shown in comparison with experimental data (where this data is available) for flow velocities, fuel, and temperature distribution. The CFD results are consistent with experimental observations for fuel distribution and vaporization.

Analysis of gas sample results, using a previously-developed NASA NOx correlation, indicates that for sea-level takeoff, the PICS configuration is predicted to deliver an EINOx value of about three for the targeted supersonic aircraft. Emissions results at supersonic cruise conditions show potential for meeting the NASA goals with liquid fuel.
\end{abstract}

\section{Nomenclature}

AST Advanced Subsonic Technology

CFD computational fluid dynamics

CFL Courant-Friedrichs-Lewy condition

$\mathrm{C}_{\mathrm{p}} \quad$ specific heat 


$\begin{array}{ll}\text { CPU } & \text { central processing unit } \\ \varepsilon & \text { turbulent dissipation } \\ \text { EINOX } & \text { emission index for oxides of nitrogen } \\ \text { ERA } & \text { environmentally responsible aviation } \\ \text { FAR } & \text { fuel-to-air ratio } \\ \text { FWHM } & \text { full width at half maximum } \\ \text { JST } & \text { Jameson-Schmidt-Turkel dissipation scheme } \\ \text { k } & \text { turbulent kinetic energy } \\ \text { LTO } & \text { landing-takeoff cycle } \\ v & \text { molecular vibrational energy } \\ \text { NCC } & \text { National Combustion Code } \\ \text { PICS } & \text { Pilot-In-Can-Swirler } \\ \text { P3 } & \text { combustor inlet pressure } \\ \text { PLIF } & \text { planar laser-induced fluorescence } \\ \text { PLS } & \text { planar laser scatter } \\ \text { T3 } & \text { combustor inlet temperature } \\ \text { SLTO } & \text { sea level takeoff } \\ \text { SRS } & \text { spontaneous Raman spectroscopy } \\ \mathbf{V}_{\text {drop }} & \text { liquid phase droplet group velocity vector } \\ \mathbf{V}_{\text {gas }} & \text { gas phase velocity vector } \\ \mathbf{V}_{\text {gas }}^{\prime} & \text { turbulent fluctuations of the gas phase velocity vector } \\ & \end{array}$

\section{Introduction}

For more than 40 years, NASA has sustained programs to reduce the environmental effects of aviation. A major focus of these programs has been reducing the emissions of nitrogen oxides (NOx). NOx emissions decrease the protective ozone layer in the stratosphere and increase smog and ozone in the lower troposphere (Ref. 1). To prevent damage to the protective ozone layer, NASA programs have focused on reducing NOx emissions at cruise conditions for supersonic flight. To reduce the emissions of NOx in the lower troposphere, NASA programs have also focused on reducing NOx emissions during the landing-takeoff cycle in subsonic flight.

In addition to decreasing NOx emissions, NASA has also addressed the reduction of carbon dioxide emissions by increasing engine fuel efficiency. Increased fuel efficiency is typically achieved by increasing the engine operating pressure ratio, which increases combustor inlet temperature; however, NOx formation rates increase with higher temperatures. Without an improvement in combustor technology, higher efficiency engines will have higher, not lower, NOx emissions: improved low-NOx combustor technologies need to be developed. NASA has defined technology targets for the near term (called "N+1", circa 2015), midterm ("N+2", circa 2020) and far term ("N+3", circa 2030) that specify realistic emissions and fuel efficiency goals for commercial aircraft. In the far term, the emissions goal for supersonic cruise is less than $5 \mathrm{~g} / \mathrm{kg}$ of fuel burned, with fuel efficiency targeted at between 3.5 to 4.5 passenger-miles per pound of fuel (Ref. 2). The Supersonics Project of the NASA Fundamental Aeronautics Program is charged with managing the challenge to develop the technologies required to meet these goals. The technical approach taken incorporates using physics-based modeling for combustion CFD to improve supersonic cruise emissions predictions, and using validation experiments to assure the models work. These models are applied to promising low emission concepts to aid in design and development. NASA has partnered with engine and fuel injector manufacturers to develop practical technology to meet the stringent emissions goals requirements. 
One such partnership is with United Technologies Research Center (UTRC), which devised a fuel injection/mixing concept to meet the far term criteria using a fuel-lean approach compatible with the cycle conditions devised for a Pratt \& Whitney supersonic transport notional engine. The concept is called the Pilot-In-Can Swirler (PICS). In the PICS injector concept, each swirler contains a pilot "can" concentrically located inside the main stage swirler (which dumps into an annulus), and in which the pilot stage flame is isolated from the main stage flame to help reduce interaction between zones for improved turndown capability. One key aspect of the concept is that the fuel for the main fuel stage is injected as a gas (Ref. 3). Gas phase fuel air mixing theoretically has the benefit of reducing the additional mixing time that would have been required for fuel atomization and vaporization. Additionally, if the fuel is able to be preheated by using it as a heat sink for cooling the aircraft, other efficiencies can be gained.

Previous evaluation of the PICS injector performed at UTRC (Ref. 3) included comparison of cold-flow gas-gas mixing measurements with analytical predictions for supersonic cruise conditions, and combustion tests at both supersonic cruise and idle conditions (pilot only) using vaporized Jet-A fuel for the main stage and non-heated, liquid Jet-A for the pilot. The gas-gas mixing results showed acceptable variation in mixture fraction at the primary swirler exit. The emissions results at supersonic cruise satisfied the NOx emissions target with combustion efficiency $>99.99$ percent, and at idle conditions also had high combustion efficiency with EINOx $<6$.

This paper reports results from CFD analysis and combustion testing conducted at the NASA Glenn Research Center, to explore PICS injector performance when using liquid (not gaseous) fuel. Testing of the PICS injector at NASA used unheated liquid fuel for all fuel circuits and all power settings, and expanded the previous test matrix. For these liquid-fuel tests at NASA, UTRC designed and fabricated a PICS injector having a reduced number of main fuel-injection orifices as compared to the earlier vaporized-fuel design. The smaller number of injection orifices ensured adequate fuel-injection velocity when using liquid fuel, which has a lower volume flow rate than vaporized fuel because liquid is more dense than vapor. Optical diagnostics techniques were applied at the combustor inlet to examine injector performance for fuel liquid versus vapor distribution and mixedness, and exhaust gas analysis was applied at the combustor exit to measure emissions. The test results are compared with CFD results produced using the National Combustor Code (NCC), specifically at supersonic cruise conditions.

\section{PICS Hardware}

The PICS injector concept, illustrated in Figure 1, consists of a pilot stage and a main stage, with turndown controlled by shifting the fuel distribution between the stages. To achieve this, the injector contains a pilot "can" centrally located within the main swirler, in which the pilot flame is isolated from the main-stage flame. When installed within a single-annular combustor dome, each injector is identical and receives the same fuel flow allocation. All tests and computations at NASA used a single PICS swirler, installed in a single 4- by 4-in. sector. The single PICS injector hardware is shown in Figure 2 and the computational envelope used for CFD is shown in Figure 3.

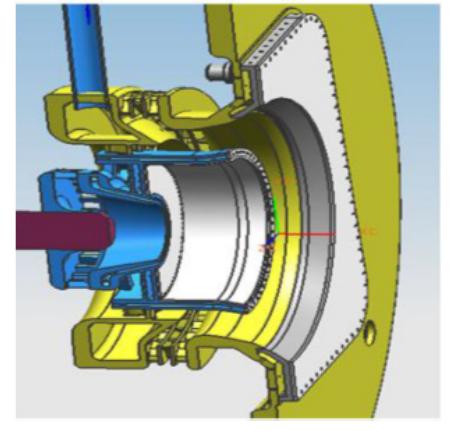

Figure 1._PICS swirler-injector concept.

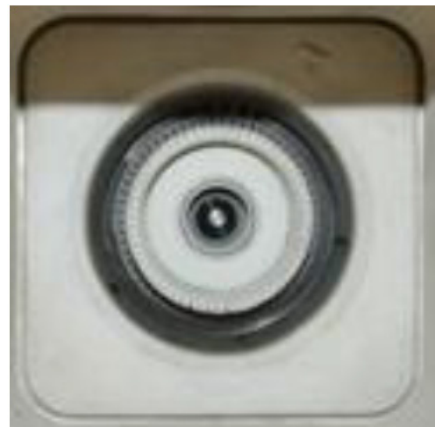

Figure 2.-Photograph of the single PICS injector, from aft-looking-forward view.

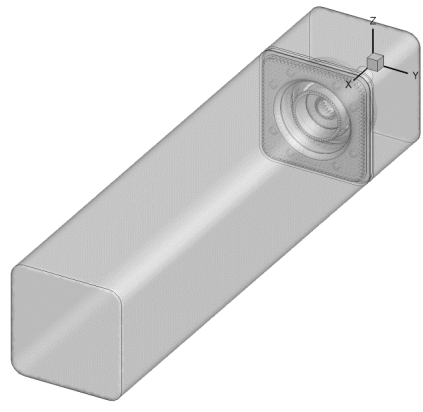

Figure 3.-Computation envelope used by the National Combustion Code for CFD simulations of PICS. 


\section{Experiment Setup}

\section{PICS Installation}

The combustor subcomponent facility at NASA Glenn supplies heated, non-vitiated air to the test rig. The test rig uses a castable ceramic to form the combustor "liner", so the four inch by four inch PICS module had adiabatic walls, rather than a water-cooled liner as used for the UTRC tests. Another difference in the NASA installation was that the test stand on which the PICS injector was installed is best suited for higher air and fuel flow rates. Because the two facilities are designed to accommodate different flows, the two sets of tests could not completely match the Pratt $\&$ Whitney supersonic cycle conditions explored in this study. Table 1 shows the Pratt \& Whitney supersonic N+3 cycle conditions. Table 2 those lists the conditions used at NASA Glenn that incorporate the laser diagnostics measurements.

\section{Laser and Optical Diagnostics}

To determine the fuel spray pattern, we acquired two-dimensional images of fuel via planar laserinduced fluorescence (PLIF) and planar laser scatter (PLS); to measure major combustion species $\left(\mathrm{N}_{2}, \mathrm{O}_{2}\right.$, $\mathrm{CO}, \mathrm{CO}_{2}$, fuel, and $\mathrm{H}_{2} \mathrm{O}$ ), we acquired one-dimensional images using Spontaneous Raman spectroscopy (SRS). We also acquired chemiluminescence images of Swan band $\mathrm{C}_{2}{ }^{*}$, which are visible in the reaction zone and show where carbon-carbon electronic transitions occur. $\left(\mathrm{CH}^{*}\right.$ and $\mathrm{C}_{2}{ }^{*}$ excited species emit light in the visible region of a hydrocarbon flame spectrum.) Setup and data acquisition are described next.

The fuel PLIF, PLS, and $\mathrm{C}_{2}{ }^{*}$ images were obtained using the same receiving optics and intensified CCD (ICCD) camera. A second set of fuel PLIF images was gathered using a second ICCD camera, located on the opposite side of the combustor. The setup is similar to that illustrated in Figure 4, in which the cameras were positioned on the sides, to image light from an angle perpendicular to the combustor flow direction. A remotely controlled filter wheel allowed us to select the appropriate filter (FWHM of $10-\mathrm{nm}$, typical) to pass light through a UV-grade, $\mathrm{f}=105-\mathrm{mm}, \mathrm{f} / 4.5$, macro camera lens. The light was then focused onto a gated, 16-bit, $1 \mathrm{k} \times 1 \mathrm{k}$ pixel array, ICCD camera having a Gen II Super-Blue-SlowGate intensifier. The gate time used was $100-n s$. The laser used was a $10-\mathrm{Hz}$, frequency-doubled $\mathrm{Nd}$ :YAG-pumped dye laser/frequency mixer system set up to produce wavelengths around 282-nm. The laser beam was formed into a sheet using a pair of cylindrical lenses, to obtain a sheet approximately $300 \mu \mathrm{m}$ thick. We typically acquired images with on-chip averages of 200 gates, and traversed across the flow along the $\mathrm{Y}$ axis in 1-mm increments. The laser sheet and collection optics were traversed together so as to maintain focus on the laser sheet. For PLIF, we collected fluorescence using a filter centered near 334-nm on one camera and near 313-nm on the other. For the elastically-scattered light of PLS, we used a filter centered near 280-nm for each camera. For chemiluminescence, we did not use the laser and collected light when positioned at $\mathrm{Y}=0$ using a filter centered at 514-nm. We collected PLIF, PLS and $\mathrm{C}_{2}{ }^{*}$ data for all test matrix conditions.

TABLE 1.-PRATT \& WHITNEY SUPERSONIC N+3 CYCLE (REF. 3)

\begin{tabular}{|l|c|c|c|}
\hline & $\mathrm{P} 3, \mathrm{psi}$ & $\mathrm{T} 3,{ }^{\circ} \mathrm{F}$ & ${ }^{\mathrm{FAR}} / \mathrm{FAR}$ \\
\hline \hline SLTO \\
SLTO & 174 & 1087 & 1.10 \\
\hline Climb-66\% & 329 & 890 & 1.00 \\
\hline Approach-32\% & 235 & 767 & 0.82 \\
\hline idle & 149 & 634 & 0.66 \\
\hline
\end{tabular}

TABLE 2.-INLET CONDTIONS USED FOR PICS TESTS WITH LASER DIAGNOSTICS

\begin{tabular}{|l|c|c|c|}
\hline Nominal cycle & $\mathrm{P} 3, \mathrm{psi}$ & $\mathrm{T} 3,{ }^{\circ} \mathrm{F}$ & FAR/FAR $_{\text {SLTO }}$ \\
\hline \hline Supersonic cruise, $\mathrm{N}+3$ & 174 & 975 & 1.24 \\
\hline$\sim$ Subsonic cruise, $\mathrm{N}+2$ & 250 & 1000 & 0.85 \\
\hline Approach, subsonic, $\mathrm{N}+2$ & 205 & 716 & 0.75 \\
\hline$\sim$ Idle, subsonic, $\mathrm{N}+2$ & 100 & 425 & 0.85 \\
\hline
\end{tabular}




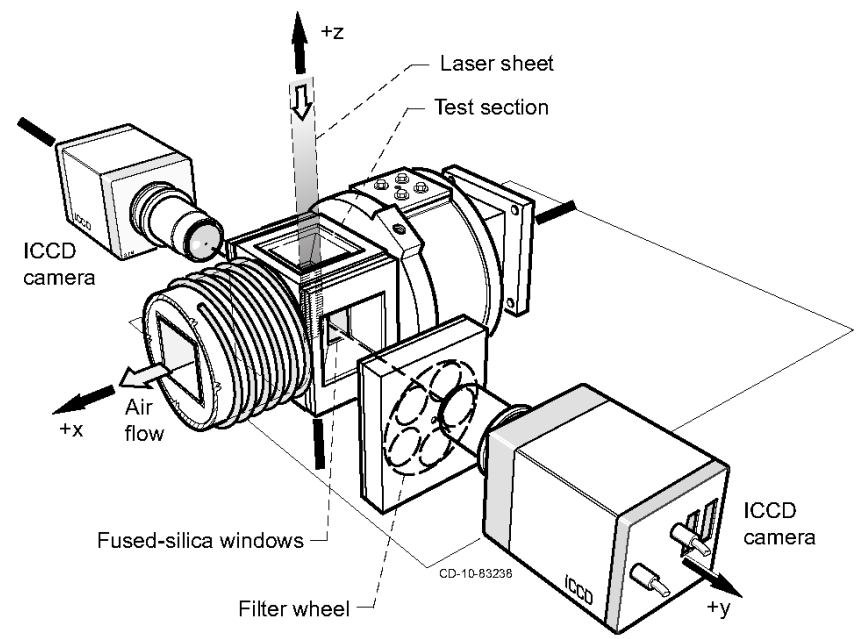

Figure 4.-Schematic drawing that shows the key components used for planar laser-induced fluorescence and planer laser scattering.

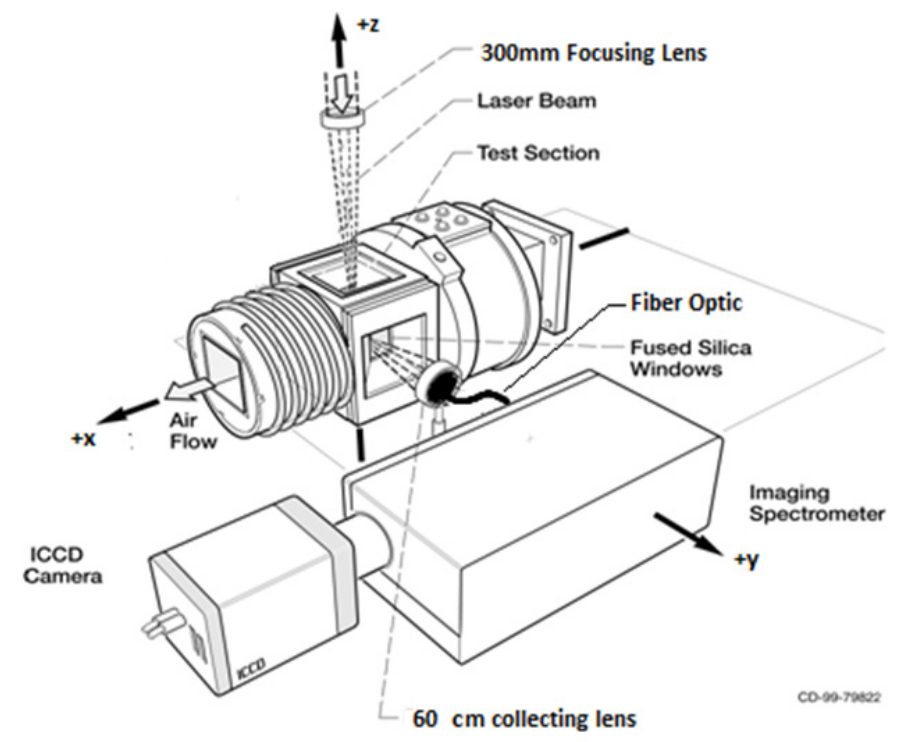

Figure 5.-llustration that shows the key components used for spontaneous Raman scattering experiments.

The spontaneous Raman species measurements were obtained using an optical arrangement similar to that shown in Figure 5. In this case, 532-nm light from a frequency-doubled Nd:YAG laser operated at $15-\mathrm{Hz}$ provided the light-scattering source. The probe volume was formed using a spherical lens, to provide a narrow, high-energy-density region from which molecules can scatter light (the SRS signal is 10-6 smaller than for laser induced fluorescence). The shape of the probe volume was defined by a combination of input and collection optics which produces a cylinder $6.67-\mathrm{mm}$ high-aligned in the vertical (z-) - with approximately a $2-\mathrm{mm}$ diameter. The scattered light from the molecules in the probe volume passed through a 550-nm long pass filter and was collected using an $\mathrm{f}=60-\mathrm{mm}$ spherical lens coupled to a vertically-oriented, linear fiber array, consisting of thirty-seven, 200- $\mu \mathrm{m}$-diameter fibers. The fiber transmitted the light to an $\mathrm{f} / 4, \mathrm{f}=300-\mathrm{mm}$ spectrometer with a 600 groove $/ \mathrm{mm}$ grating blazed at $500 \mathrm{~nm}$. The light dispersed by the grating was focused onto a High Q Blue, gated, intensified camera having an array size 1024-pixel-wide by 256-pixel- high. The camera CCD pixel size combined with the 600 line $/ \mathrm{mm}$ grating produced a $\sim 0.1667 \mathrm{~nm} /$ pixel spectral resolution. The camera array was binned in 
the spatial (vertical) dimension into five rows, each 40 pixels high, with the remaining pixels not used. These five rows provide for simultaneous measurement at five discrete locations in the z-direction. Sets of 100, 10-gate on-chip averages were collected at each position traversed in $\mathrm{x}$ and $\mathrm{y}$. The five binned rows created five spectra in which the peaks were used to identify the relative species concentrations. The use of Raman was restricted to those inlet conditions expected to have little or no liquid fuel so that the interference from Mie scatter is minimized; Mie scatter has a signal roughly a million times greater than SRS.

For all measurements, there may be a slight difference in the true spatial coordinates because the heated inlet air causes the test rig will to shift axially (x-), horizontally (y-) and rotationally about its centerline. We took measures during the tests to account for translations, but the rotation was hard to quantify and not addressed.

\section{PICS Modeling}

\section{The National Combustion Code}

The National Combustion Code (NCC) is a state of the art CFD program specifically designed for combustion processes. A short summary of the features of the NCC pertaining to this paper are: the use of unstructured grids (Ref. 4), massively parallel computing — with almost perfectly linear scalability (Refs. 5 and 6) on non-spray cases up to four thousand central processing units (CPU), a dynamic wall function with the effect of adverse pressure gradient (Ref. 7), low Reynolds number wall treatment (Ref. 8), and a cubic non-linear k-epsilon turbulence model (Refs. 9 and 10), lagrangian liquid phase spray model, and stiff laminar chemistry integration. Recently, viscous low-speed preconditioning (Refs. 12 and 13) has been added to improve the low-speed convergence of the NCC in viscous regions. The combination of these features is usually not available in other CFD codes and gives the NCC an advantage when computing recirculating, turbulent, reacting, spray flows. Previously, the NCC has undergone extensive validation studies for simple flows (Ref. 14), complex flows (Ref. 15), $\mathrm{NO}_{\mathrm{x}}$ emissions prediction performance (Ref. 16), and traditional gas turbine combustor/injectors (Ref. 17).

\section{Geometry and Mesh Generation}

UTRC created the orginial PICS solid model using NX (Ref. 18) and transferred it to NASA in ParaSolid format as an "air-solid", the solid geometry that only represented the fluid flowing through the PICS combustor and NASA test cell. The file was then imported into SolidWorks, "regenerated" and exported as an ACIS (Spatial Corporation, Broomfield, CO) file. The ACIS file was then imported into Cubit (Ref. 19) for automatic geometry clean up and manual simplification, while also removing surface artifacts (like holes where tubes once existed) from the simplification process.

The single, simplified "air-solid" was then imported as an IGES file into Pointwise (Ref. 20). Because ignition transients tended to greatly increase wall clock computational time as mesh size increased, an optimized mesh of 5.5 million isotropic tetrahedral elements was generated. We believe this mesh balanced accuracy and reasonable solution time for this engineering effort. Non-reacting simulations were run as a check using a stretched tetrahedral mesh of 18 million elements. The 5.5 million element matched the global pressure drop to within 20 percent of the 18 million element mesh value.

\section{Chemistry Modeling}

Ideally, we would prefer to use detailed chemical kinetic models. There are two problems with this approach: (1) Jet-A is a multi-component fuel and not a substance, and there are no universally accepted surrogate fuel models for Jet-A; (2) the computational costs associated with these models make them impractical when fine computational grids are used. Originally, a single-step, global chemistry model was used. This model was based on propane kinetics (Ref. 21), which are close to Jet-A's reaction rates. The Jet- $\mathrm{A}$ fuel is modeled as single species $\left(\mathrm{C}_{11} \mathrm{H}_{21}\right)$ that represents a hydrocarbon mixture of decane, hexane 
and benzene in both gas-phase and liquid-phase solvers. The gas is treated as an ideal mixture with five-coefficient curve fits for $\mathrm{C}_{\mathrm{p}}(\mathrm{T})$ of each species and a CHEMKIN treatment of transport properties (species and ideal mixture rules). The single-step model allowed an easier start up in the solution process, by reducing the computational requirements during the ignition phase. Single-step models do not allow emissions calculations, only heat release. Because of this, a reduced twenty-step, fifteen species model was used based on the mechanism published in Ajmani-Kundu (Ref. 22). The reduced mechanism also describes the formation of Carbon Monoxide and Nitrogen Oxide. However, only one nitrogen-oxide species, NO, has been used in the reduced mechanism. NO in the reduced mechanism represents the whole family of nitrogen oxides including nitric oxide by Zeldovich (Ref. 23) reactions, prompt NO reactions by Fenimore (Ref. 24), and nitrogen oxide formation through nitrous oxide.

\section{Liquid Phase Modeling}

The liquid Jet-A spray is evolved using a dilute spray Lagrangian solver (LSPRAY) (Ref. 4) which neglects any drop-drop interactions. Turbulence effects follow the KIVA-II approach (Ref. 25) of adding a turbulent fluctuation velocity to gas-phase velocity when calculating droplet drag and vaporization. The evaporation model includes solution of internal drop temperature distribution (thirteen point onedimensional mesh, finite-difference solution of a Hill vortex model) and a droplet regression rate employing three different correlations depending on droplet Reynolds number, $\operatorname{Re}_{\text {drop }}$ (where $\operatorname{Re}_{\text {drop }}$ is based on the relative speed $\mathbf{V}_{\text {gas }}+\mathbf{V}_{\text {gas }}^{\prime}-\mathbf{V}_{\text {drop }}$ ).

Jet-A fuel was represented as a single component, $\mathrm{C}_{11} \mathrm{H}_{21}$. Fuel injection, atomization, and evaporation were handled in the following manner. Fuel injection in the model was handled by using Lefebvre's (Ref. 26) airblast correlations for a plain orifice. The correlation provided mean fuel droplets sizes of $16.3 \mu \mathrm{m}$ for the main fuel circuit and $13 \mu \mathrm{m}$ for the pilot. These particles are then injected, assuming a Rosin Rammler drop size distribution (Ref. 27), in the appropriate locations in the model, as jets in crossflow. These jets were presumed to have a solid cone angle of $7^{\circ}$, with each cone represented by eight circumferential droplets groups, with eight polar droplets groups at each circumferential location, stochasitally injected (with respect to polar and circumferential locations) every 200 spray solver time steps $(40 \mu \mathrm{sec})$. The main and pilot circuit drops were injected with velocities of 42 and $13 \mathrm{~m} / \mathrm{s}$, respectively. Once in the flow, the particles were tracked $0.2 \mathrm{msec}$ before evaporation was switched on.

\section{Computational Procedure}

The simulations are steady-state and solve the Favre-averaged transport equations for species, momentum and energy, as well as a two-equation k- $\varepsilon$ turbulence model. Staging was used in the solution process; cold-flow calculations and initial combustion calculations were performed using a single-step chemistry model with lagrangian spray until a steady state solution was obtained. The final stage of CFD calculations was performed by switching from the one-step chemistry model to the reduced chemistry model; this was done by changing the input chemistry-parameters of the code. It is important to note that no turbulence-chemistry interaction model was used for this case, so called "laminar chemistry". So, averaged temperature and averaged mass fractions were used to compute the reaction rate. We believe this is appropriate as an engineering assumption, because for this particular case, turbulent kinetic energy (k) is below $20 \mathrm{~m}^{2} / \mathrm{s}^{2}$, with the peak on occurring at the tip of the fuel injector.

Calculation of the source term due to chemical kinetics uses the explicit "reference species" approach described in the KIVA-II manual. In the current implementation, the explicit "reference species" integration of chemical kinetics source is performed using ten sub-iterations within each pseudo-time step of gas-phase Runge-Kutta integration in pseudo-time.

The NCC computations for reacting and non-reacting flow were run in general until the flow residuals were reduced three orders of magnitude. The mass flow rates at the boundary conditions were also monitored as a convergence criterion. Dissipation (JST type) was set at 0.0 for second order dissipation $\left(\varepsilon_{2}\right)$ and 0.05 for fourth order dissipation $\left(\varepsilon_{4}\right)$ (Ref. 28). The value of $\mathrm{k}_{2}$, the constant that scales the second 
order dissipation gradient switch, was set at 0.70 . Setting the second order dissipation to zero is absolutely necessary to accurately resolve flow features, like jets. A CFL number of 1.0 was used. A cubic, nonlinear k-epsilon model with a variable $\mathrm{C}_{\mathrm{mu}}$ coefficient was used. This model was selected because of the swirling flow. A dynamic wall function with pressure gradient effects was used to model near wall turbulent flow effects.

Computations were performed on the SGI ICE computer "Pleiades" at NASA Ames. The "Pleiades" supercomputer with "Ivy Bridge" processors was preferred because its processor cores had considerably higher computational performance and because of its high speed, low-latency interconnect. This interconnect was important because the Lagrangian spray model created a load unbalance in compute nodes. The high speed interconnect seemed to mitigate the load imbalance. It takes approximately one week (wall clock) to complete a single PICS combustion case (starting from no initial solution) using 960 processors.

\section{Results and Discussion}

Along with the emissions results obtained by gas sampling at the combustor exit, we present the CFD results for supersonic cruise and compare those with measured fuel patternation and Raman fuel and $\mathrm{CO}_{2}$ concentrations relative to nitrogen. We also compare cases related to the ERA subsonic $\mathrm{N}+2$ cycle for approach and elevated "idle" conditions, for fuel patternation via PLIF and PLS only.

\section{Supersonic Cruise}

Figures 6 to 9 show highlights of the CFD results at the N+3 supersonic cruise conditions run at NASA Glenn using fuel at ambient temperature. Later, we compare the simulated results with the laserbased measurements. The mean velocities and vorticity are shown in Figure 6, while Figure 7 shows the temperature distribution. Figures 8 and 9 show the $\mathrm{OH}$ and fuel profiles, respectively.

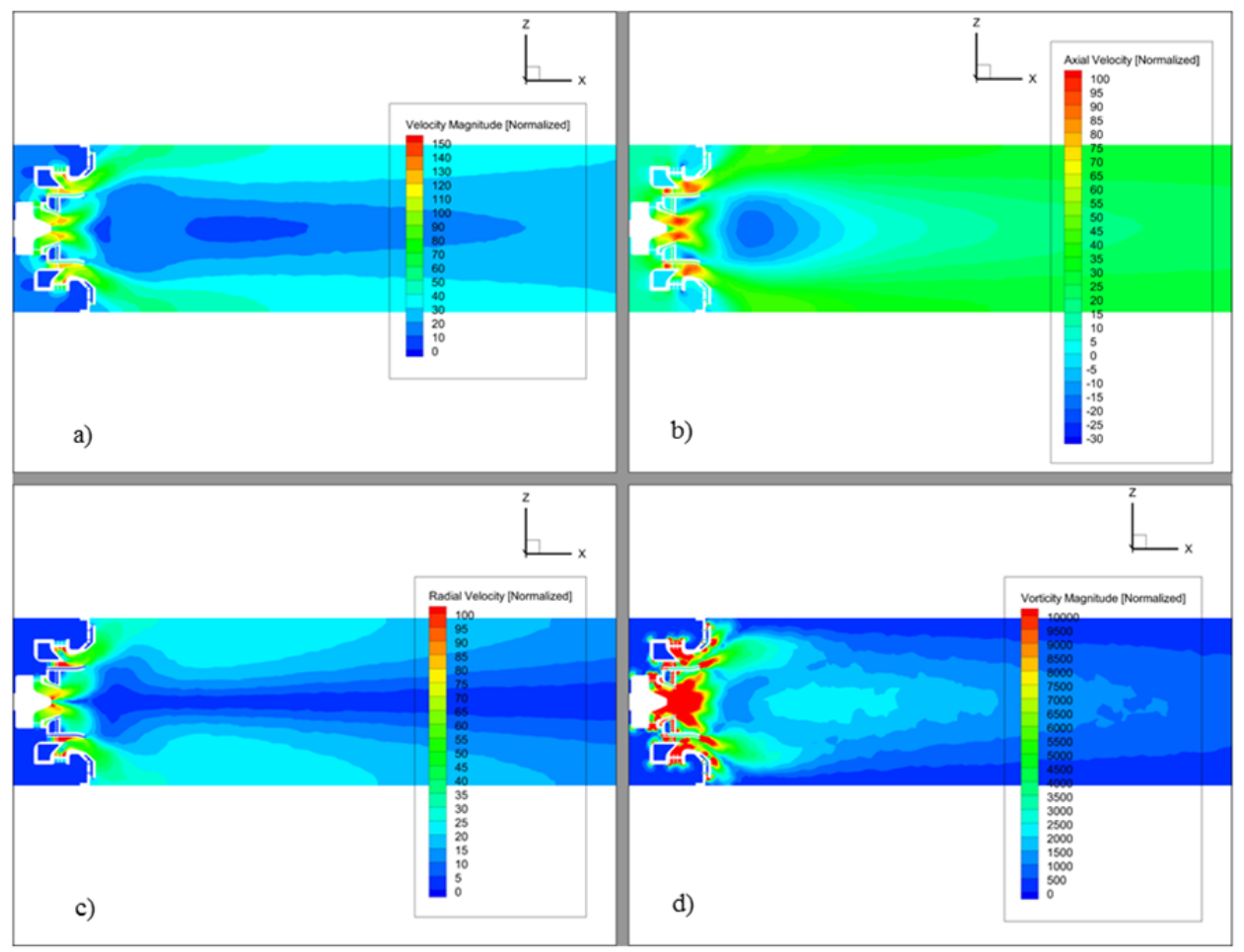

Figure 6.-CFD results: normalized velocity and vorticity for $\mathrm{N}+3$ supersonic cruise at center of combustor. Flow is from left to right. a) total velocity; b) axial velocity; c) radial velocity; d) vorticity. 


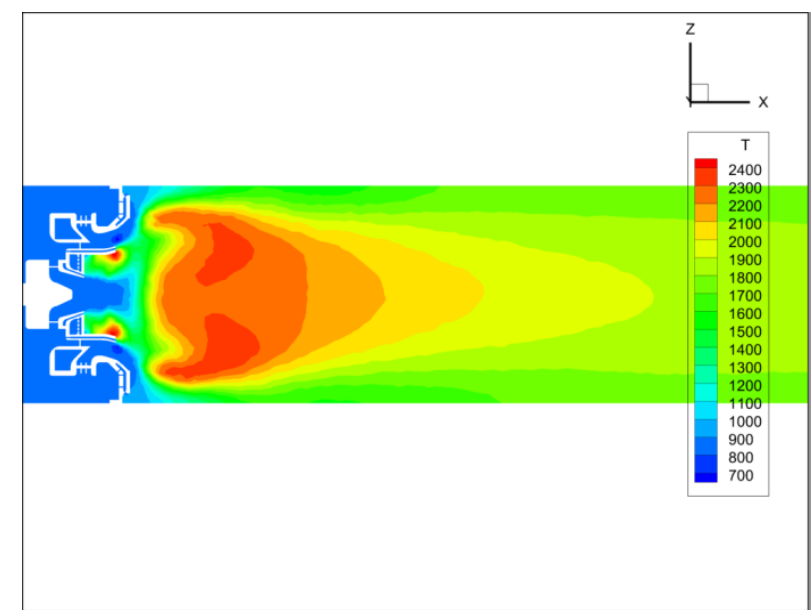

Figure 7.-CFD results: Predicted contours of temperature within the $Y=0$ plane of the PICS combustor at the $\mathrm{N}+3$ supersonic cruise condition. Flow passes from left to right.

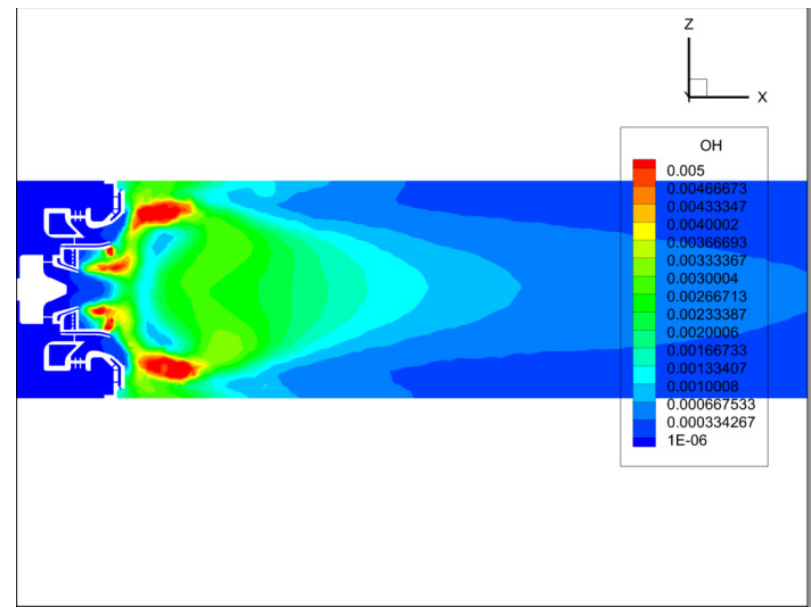

Figure 8.-CFD results: Predicted contours of $\mathrm{OH}$ mole fraction within the $Y=0$ plane of the PICS combustor at the $\mathrm{N}+3$ supersonic cruise condition. Flow passes from left to right.

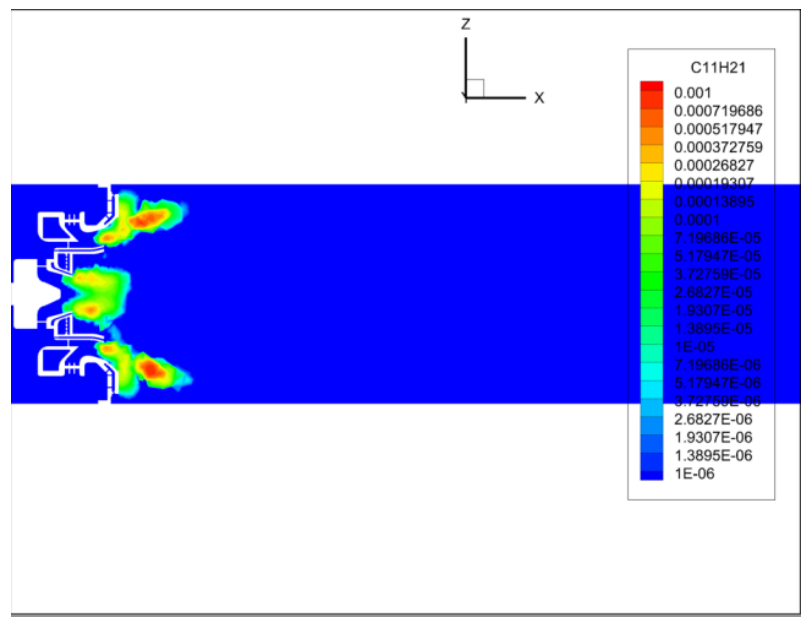

Figure 9.-CFD results: Predicted contours of fuel mole fraction within the $Y=0$ plane of the PICS combustor at the $\mathrm{N}+3$ supersonic cruise condition. Flow passes from left to right.

The PICS generates high radial velocity and vorticity within the swirler, which translates to a strong central recirculation zone immediately downstream from the swirler to help promote flame stability. The highest temperatures, from about 2200 to $2400 \mathrm{~K}$ extend as far downstream as the recirculation zone and are bounded radially by the mid-level vorticity (with values on the order of $5500 \mathrm{~s}^{-1}$ ).

Figures 8 and 9 show the predictions for $\mathrm{OH}$ and fuel. We see high levels of $\mathrm{OH}$-which show areas of reactivity and temperature - in the regions where fuel and air mix, so the regions of Jet-A (as represented by $\mathrm{C} 11 \mathrm{H} 21$ ) coincide with high $\mathrm{OH}$. Most of the $\mathrm{OH}$ occurs within the recirculation zone, but secondary and tertiary reactions persist downstream until reactions are complete. Fuel from the main stage projects downstream approximately to the axial location coinciding with the maximum reverse flow velocity and radially outside of the recirculation zone. This allows us to compare the fuel spray as measured using PLIF, PLS, and SRS to the CFD analysis. 
The optical measurements occurred beyond the PICS “dump plane" which is the injector's downstream-most vertical end surface. Figures 10 to 15 show the results obtained at supersonic cruise conditions. The PLIF signal - representing fuel liquid and vapor - arises from the family of compounds having double ring aromatics (naphthalene $-\mathrm{C}_{10} \mathrm{H}_{8}$ ), as its base, such as methylnaphthalene. PLS signal arises from the Mie-type scatter presumedly of liquid phase fuel droplets on the order of $280 \mathrm{~nm}$ and larger. The SRS fuel signal is derived from the spectral region of the main $\mathrm{C}-\mathrm{H}$ stretch, having a Raman shift near $3015 \mathrm{~cm}^{-1}$, near methane $v_{1}$ and $v_{2}$ and ethylene $v_{1}$ vibrational energies. The SRS signals for fuel and $\mathrm{CO}_{2}$ are presented as mole fractions, normalized to molecular nitrogen. The PLIF and PLS signals are measured in counts of signal and presented on a linear scale. The signals are scaled separately to ease comparison.

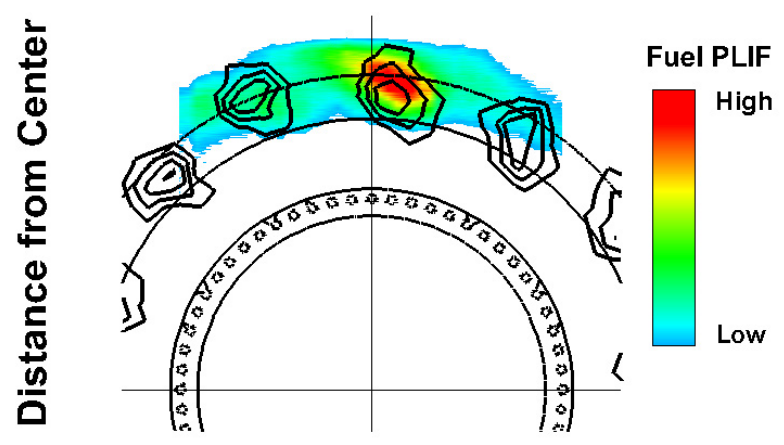

Distance from Center

Figure 10.-PICS Fuel pattern in an axial slice at the supersonic cruise condition: CFD prediction as line contour, with measured PLIF as color contour. Aftlooking-forward perspective.

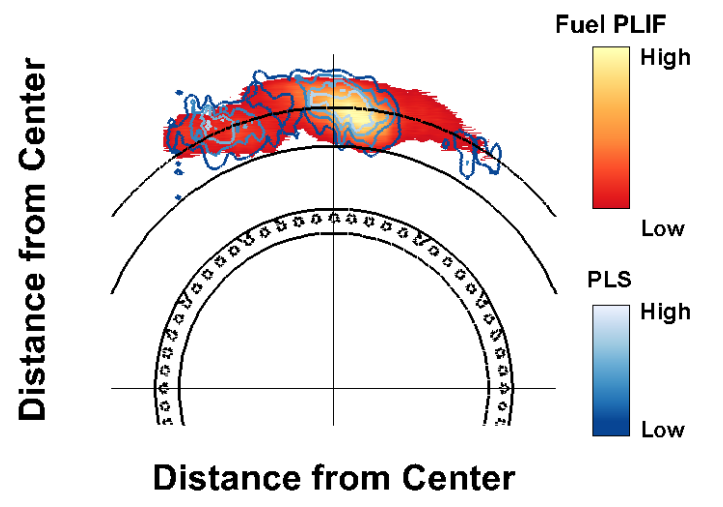

Figure 12.-Supersonic cruise result: Comparison between total fuel signal represented by Fuel PLIF (red-yellow contour) and liquid fuel from PLS (blue contour). Perspective view is aft-looking-forward.

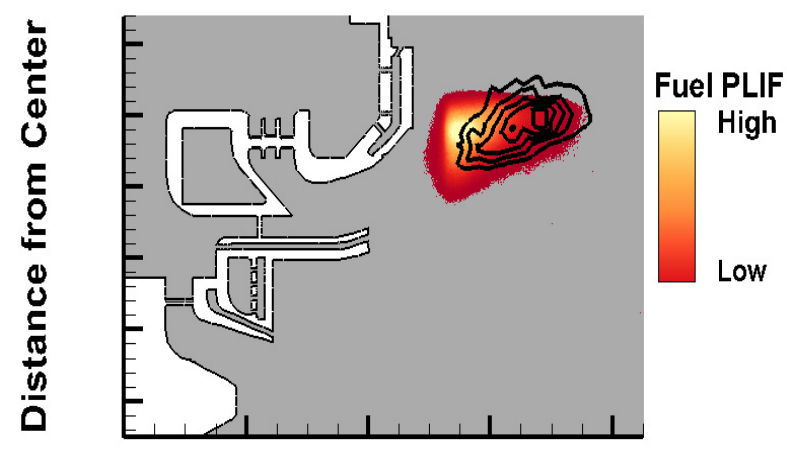

Axial Distance

Figure 11.-Comparison at supersonic cruise condition between predicted Jet-A (line contour) and measured fuel PLIF (color contour) distribution in the center vertical plane, at $Y=0$. Flow is from left to right.

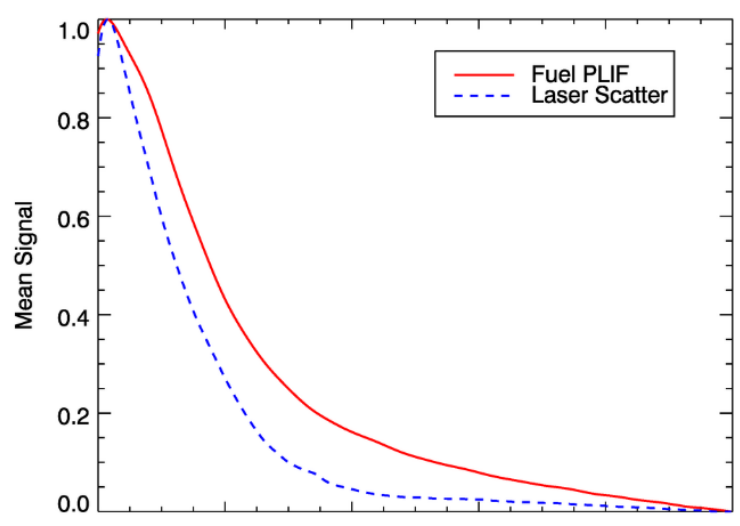

Axial Distance

Figure 13.--Supersonic crise result: Comparison showing the decay of liquid fuel (laser scatter, dashed, blue line) to Fuel PLIF (liquid+vapor, solid red line) at supersonic cruise. Each plot is normalized using its maximum signal. 


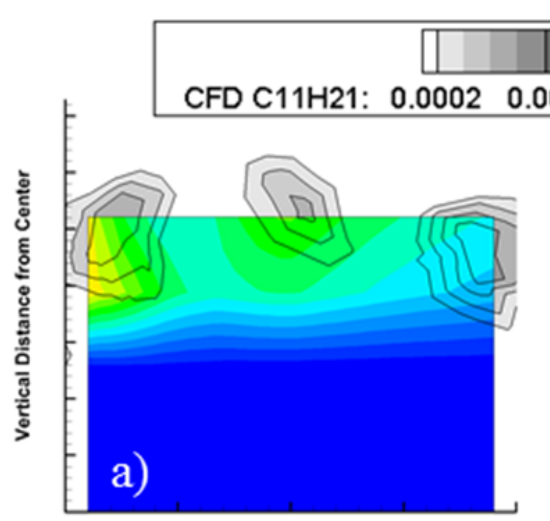

Horizontal Distance from Center
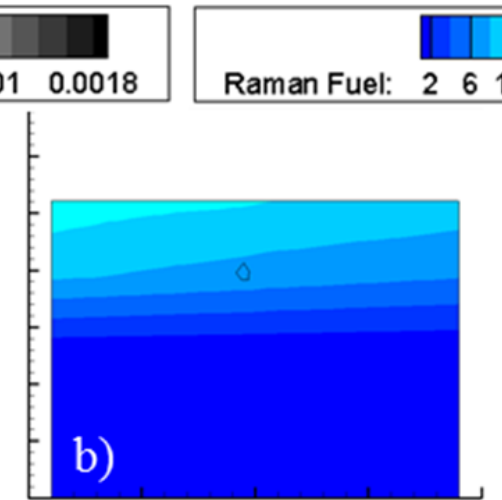

Horizontal Distance from Center
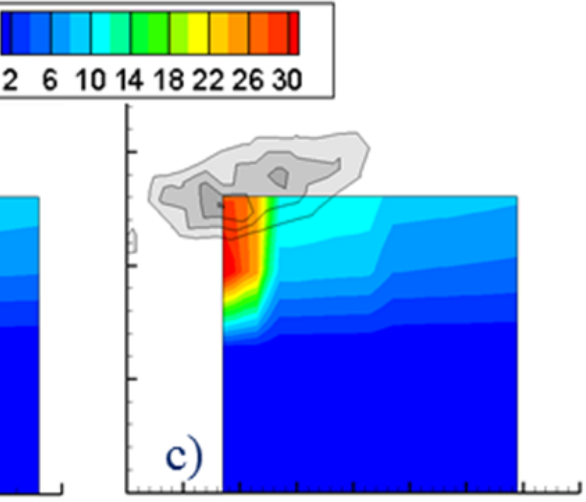

Axial Distance Downstroam

Figure 14.-Fuel fraction contours determined using CFD (grayscale, with lines) and SRS (color) at supersonic cruise condition. a) and b) are presented as axial slices, from the perspective of aft-looking-forward, with a) near the dump plane and b) $10 \mathrm{~mm}$ downstream. The 14c) image shows a center vertical slice with flow from left to right.

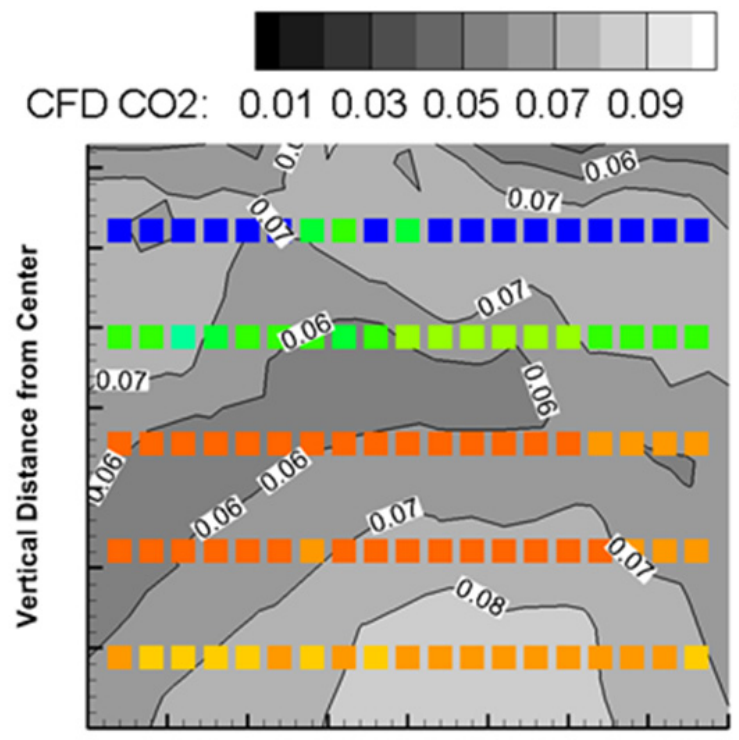

a)

Horizontal Distance from Center

Raman $\mathrm{CO} 2$ :
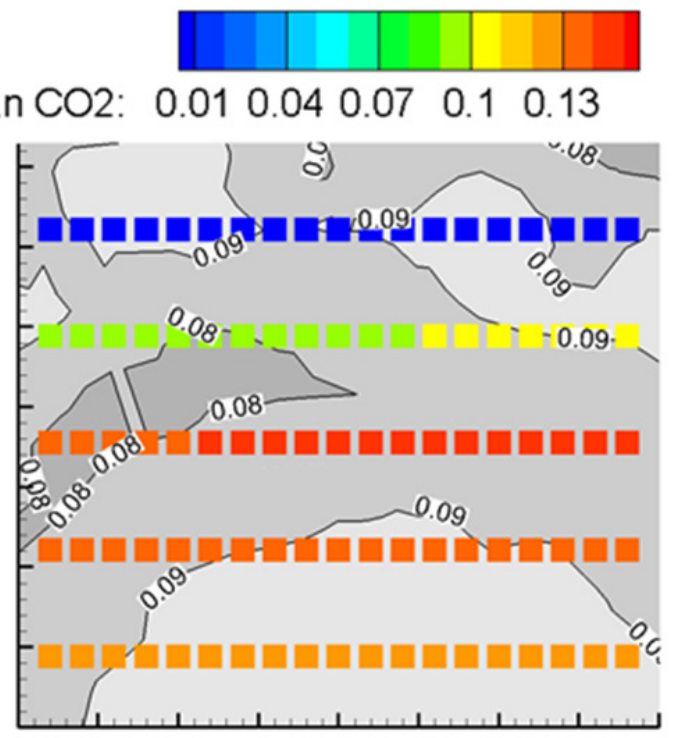

b)

Horizontal Distance from Center

Figure 15.-Predicted and measured $\mathrm{CO}_{2}$ signals within two axial slices, supersonic cruise condition. a) near the PICS dump plane, and b) $10 \mathrm{~mm}$ downstream. CFD results are presented as labeled, gray scale contours and the SRS results are scatter plots, wit size represented by color. The perspective is aft-looking-forward.

Figures 10, 11, and 14 show the fuel pattern for PLIF or SRS, each overlaid with CFD results at the corresponding spatial locations. The PLIF and PLS images were obtained on the same day, within minutes of each other; the SRS data were obtained on a different day. In each case, fuel signal emanates from a different "species". Results from the optical techniques compare well with the numerical predictions, and show the fuel-air mixture is not uniform, which is to be expected because the fuel was injected at room temperature. There was not enough time for complete vaporization and mixing before exiting the main swirler. The amount of liquid compared to vapor can be seen qualitatively in Figure 12, which shows the fuel PLIF signal (in red-yellow tones), comprised from both liquid and vapor signals; along with the PLS signal (blue tones), which is from the liquid fuel. Of the cases tested, this supersonic cruise point exhibited the highest signal from both PLIF and PLS. The two signals overlap almost totally to show that the fuel at this axial location is mostly in the liquid phase. Figure 13 shows the decay of fuel signal with axial distance from the dump plane for PLIF( solid red line) and PLS (dashed blue line). The mean signal was computed by calculating the average total signal at each axial location within the data 
blocks, then normalizing based on the respective maximum signal. The liquid signal decays at a faster rate than the total signal. We assume the fuel is effectively vaporized when the PLS signal reaches 5 percent of the maximum. Using this assumption, the fuel is evaporated an axial distance approximately 60 percent of the distance it takes the total remaining fuel to be consumed.

Figures 11 and 14(c) show, respectively, the fuel PLIF and SRS signals, along with the CFD fuel in the $\mathrm{y}=0$ plane, just downstream from the PICS dump plane. One may notice in Figure 11 that the fuel PLIF signal contour is flat at the top; this marks the top of the optical field-of-view. All show similar results in that the fuel is projected outward and downstream from its origin. The slight displacement between measurements might be for a number of reasons. For example, the inlet conditions can vary slightly from one test day to the next. Setup of the two imaging techniques uses different equipment and necessarily different fiducials to designate a home reference position for the optics. SRS measurement results may also appear displaced because of the low spatial resolution of the measurement volume compared to the CFD or PLIF resolution; thus for example, the SRS fuel signal in Figure 14(c) appears somewhat lower compared to the CFD. Also noted earlier, the test rig shifts depending on the inlet conditions, and some misalignment may occur based on rig growth. Although the CFD requires compromise in choices of models, mesh, and computational procedure, among others, it represents a physical ideal, while the research hardware, in particular, is likely to have some machining non-uniformities or imperfections and undergoes wear and tear for each test installation and as time progresses.

Figure 15 shows the results for carbon dioxide. The CFD mass fractions are shown as grayscale line contours, with the contours labeled. The SRS data are shown as a color scatter plot, with the symbols sized based on the concentrations relative to molecular nitrogen. From the CFD, we see that $\mathrm{CO}_{2}$ concentration peaks in two regions: centrally, immediately downstream from the pilot; and in the annular region downstream from the main. The greater amount is near the pilot. For the Raman measurement, we found more $\mathrm{CO}_{2}$ near the pilot, with decreasing amounts as one moves radially outward to the main region. The discrepancy of there being very little relative $\mathrm{CO}_{2}$ concentration near the main may be due to an increase in luminosity in the background. The increase in background luminosity for the top two rows of the detector is approximately thrice and twice that of the bottom three rows. The source of the increased luminosity might be flame chemiluminescence arising from the main flame that is just above the field of view, or from blackbody radiation emitted by the casting, which is also just above the field of view. This increase in background luminosity decreased the signal to noise ratio to a level such that the signal was obscured. The plot in Figure 15(b) is located $10 \mathrm{~mm}$ downstream from Figure 15(a), and shows an increase in the amount of carbon dioxide including the area immediately downstream from the main annulus; the result is consistent with expectation and also with the thought that fuel interferences have some effect on the measurements in the region of the main injector.

\section{Subsonic N+2 Cases}

NASA's N+2 subsonic engine is expected to have a larger core than the supersonic N+3 engine, and higher operating pressures. Thus, it has higher air and fuel flows in its cycle. We provide a brief synopsis of results.

\section{Subsonic Cruise}

Figure 16 shows an axial slice (aft-looking-forward perspective) near the dump plane, for the subsonic cruise condition (Table 2). We saw earlier that test conditions using fuel at ambient temperatures still exhibit a good deal of fuel in the liquid state after entering the combustor. However, for this condition, we determined using the method described above, as well as considering the total PLS and PLIF relative signals, that at most 10 percent of the total fuel signal was from the liquid. The higher inlet temperature and pressure, along with the commensurate higher flow rates and lower FAR contributed to higher vaporization and mixing, which is reflected in the more uniform fuel distribution compared to that shown in Figure 12 for the supersonic cruise condition. This case also performed well for emissions, with EINOX $<5$. 


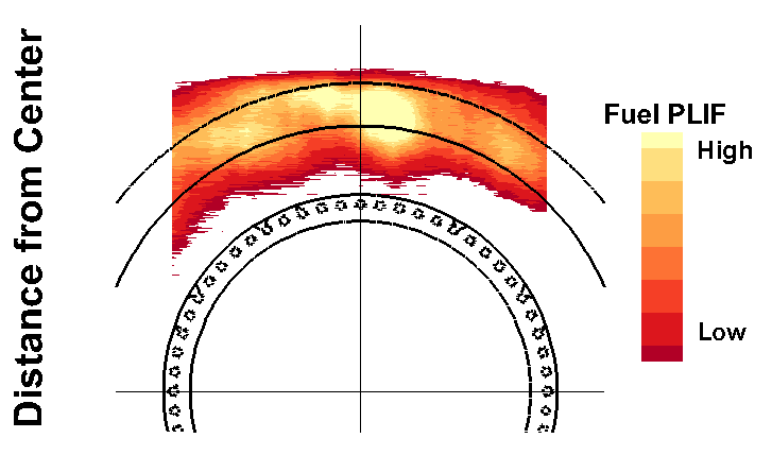

\section{Distance from Center}

Figure 16.-Result for $\mathrm{N}+2$ Subsonic Cruise. Fuel pattern near dump plane for subsonic cruise condition as tested at NASA Glenn. The

\section{Approach} perspective is aft-looking-forward.

Figures 17 and 18 show results from two cases for approach conditions (Table 2), one with fuel staging between pilot and main (Approach-1), the other using pilot only (Approach-2). The gas analysis results showed higher NOx levels for Approach-2 with EINOX 27 percent higher than for Approach-1. Approach-1 used approximately 8 percent more fuel than Approach-2, with all other inlet parameters equal. In this comparison, the local equivalence ratio was important. Figures 17(a) and 18(a) show fuel patternation at the same axial position, using PLIF and PLS, and show that Approach-2 is less mixed than Approach-1. We also noted for Approach-1 that the PLS raw signal exceeded the PLIF signal; this is the only point tested for which this was the case, and indicates the majority of fuel was in the liquid phase. Figures 18 (b) and 19(b) show the corresponding $\mathrm{C}_{2}{ }^{*}$ chemilumenescence, obtained by computing the mean from 200 instantaneous images, with exposure time for each image of $100 \mu \mathrm{s}$. Flow is left to right. These images give an indication of where much of the carbon-carbon breakup occurs. Reactions are occurring closer to the dome for Approach-1 (implying reactions will be completed sooner), and without as much total intensity, than for Approach-2. These results indicate that if possible, fuel staging will be a better option for emissions during approach than running with pilot only.

\section{Idle}

The results at the elevated pressure idle condition (Table 2) are presented in a similar fashion as for the approach cases, in Figures 19 (case Idle-1) and 20 (Idle-2). The idle cases use only the pilot and case Idle1 has FAR 1.7 times case Idle-2, with both running fuel-rich. In this comparison, Idle-1 has less uniformity in fuel pattern and much more reactivity farther downstream, and resulted in higher EINOX levels.

\section{Emissions Measurements}

NOx emissions results from the NASA liquid-fuel tests are presented in Figure 21, for PICS injector operation over a range of inlet conditions. For these emissions tests, combustor inlet pressure was varied from 150 to $255 \mathrm{psia}$ (including the 175 psia supersonic cruise inlet pressure), and combustor inlet temperature was varied from 850 to $1004^{\circ} \mathrm{F}$ (about $80^{\circ} \mathrm{F}$ below the supersonic inlet temperature). The measured EINOx data for all of these conditions are plotted, and show only weak dependence on inlet pressure and temperature over this range. Combustion efficiency was greater than 99.95 percent for all data points shown. Based on the raw measured NOx data, the PICS injector appears to deliver about 5 EINOx at the supersonic cruise fuel-air-ratio, FAR/FAR SLTO $=1.1$, when operated on liquid-fuel only (i.e., unheated fuel that is not vaporized) in the NASA rig, at the combustor inlet temperatures and pressures listed. 

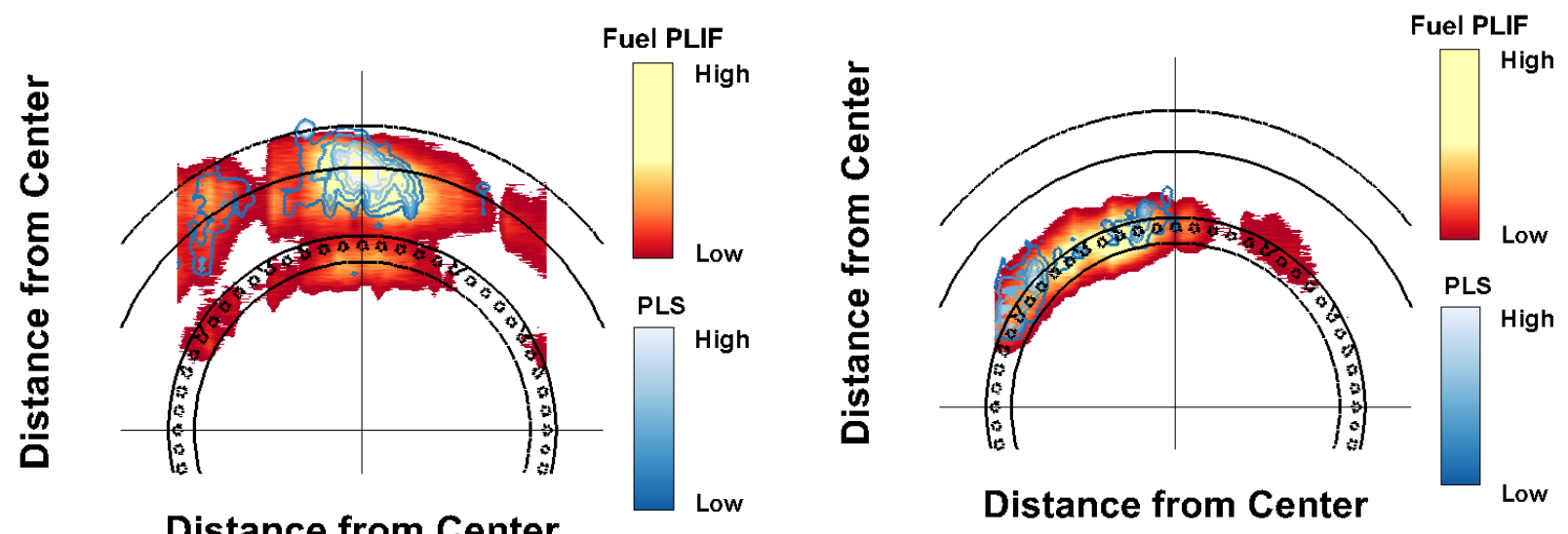

a)

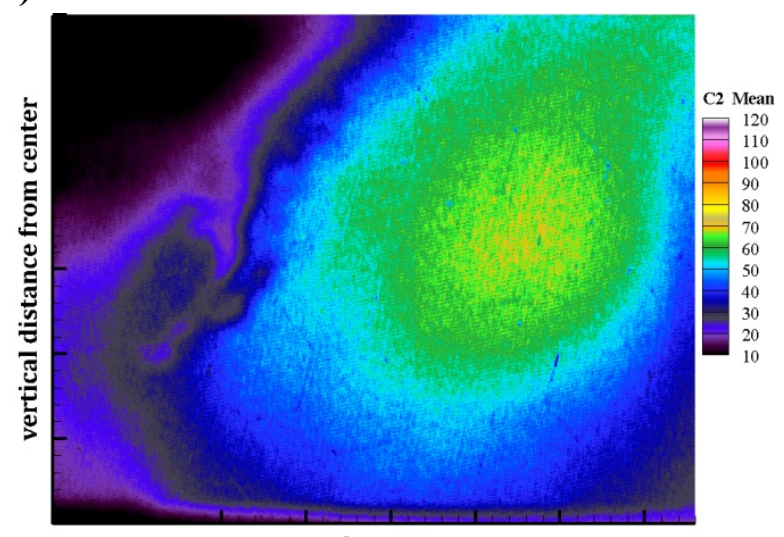

b)

a)

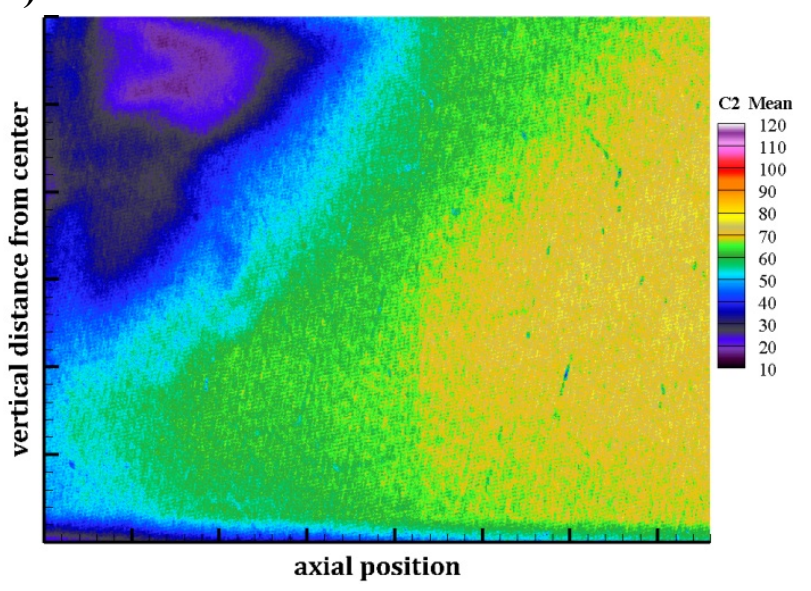

b)

Figure 17.-Results from Approach-1. a) Total fuel signal represented by Fuel PLIF (red-yellow contour) and liquid fuel from PLS (blue contour), viewed aft-lookingforward. b) Mean $\mathrm{C}_{2}{ }^{*}$ chemiluminescence signal within the vertical central plane $(Y=0)$ obtained by computing the average of 200 individual images. Flow is left to right.

Figure 18.--Results from Approach-2. a) Total fuel signal represented by Fuel PLIF (red-yellow contour) and liquid fuel from PLS (blue contour), viewed aft-lookingforward. b)Mean $\mathrm{C}^{*}$ chemiluminescence signal within the vertical central plane $(Y=0)$ obtained by computing the average of 200 individual images. Flow is left to right. 

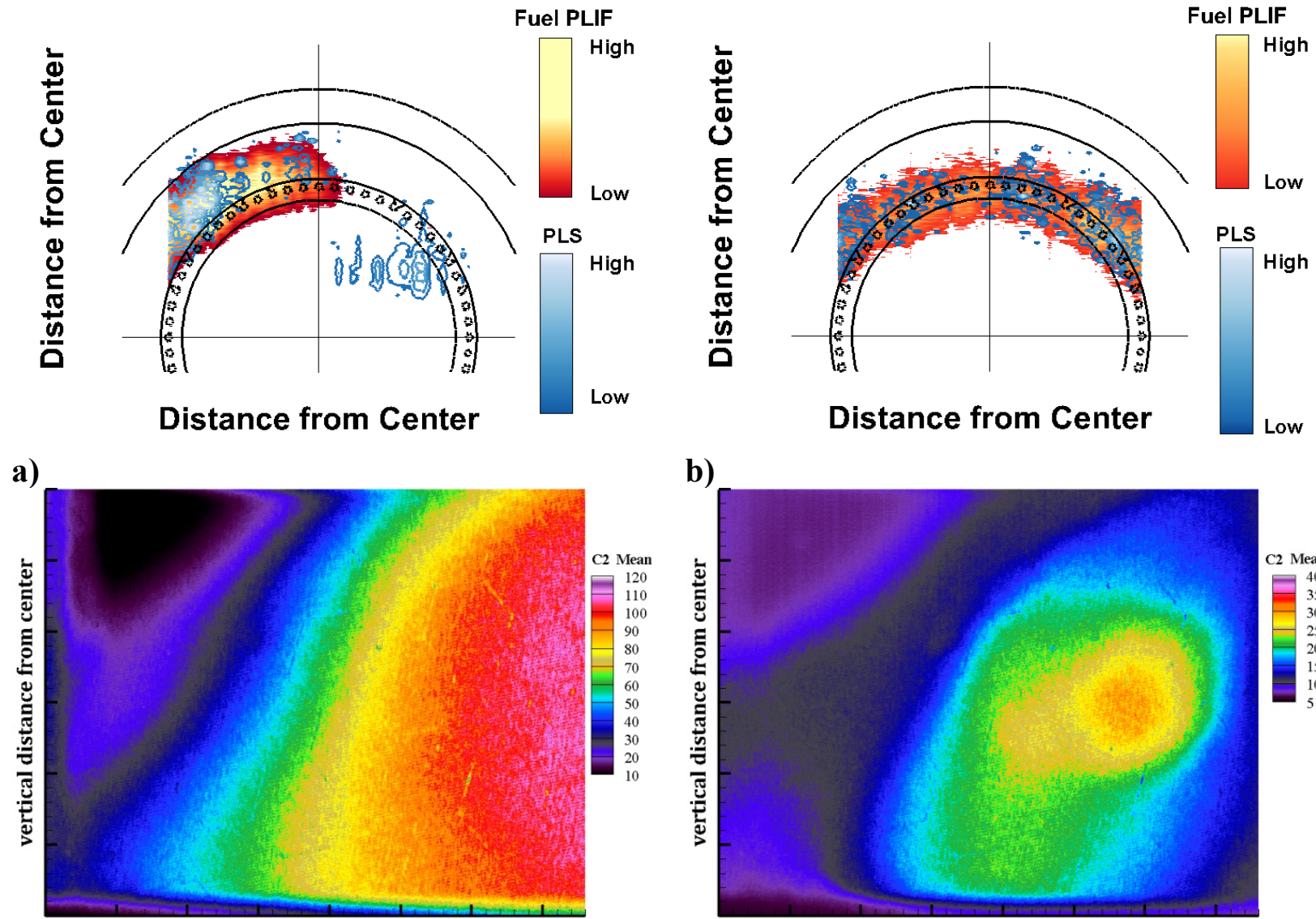

a)

b)

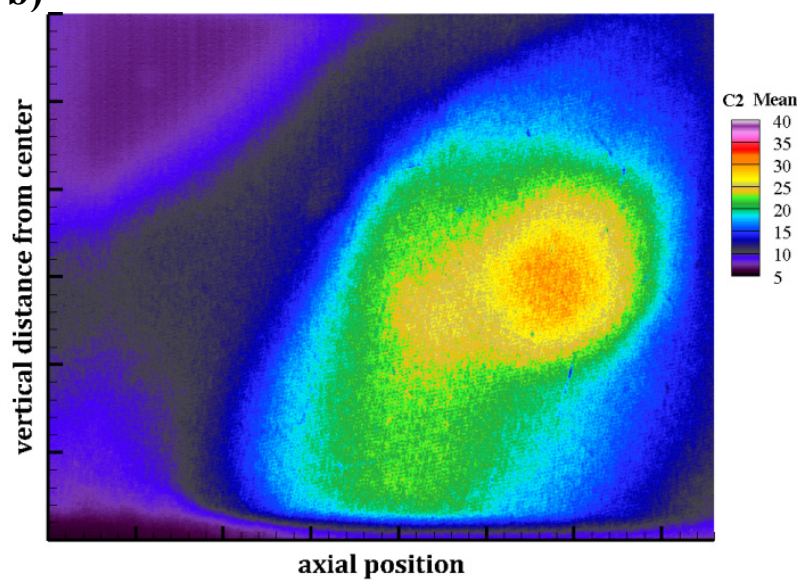

b)

Figure 19.--Results from Idle-1. a) Total fuel signal represented by Fuel PLIF (red-yellow contour) and liquid fuel from PLS (blue contour), viewed aft-lookingforward. b)Mean $\mathrm{C}_{2}{ }^{*}$ chemiluminescence signal within the vertical central plane $(Y=0)$ obtained by computing the average of 200 individual images. Flow is left to right.

Figure 20.-Results from Idle-2. a) Total fuel signal represented by Fuel PLIF (red-yellow contour) and liquid fuel from PLS (blue contour), viewed aft-lookingforward. b)Mean $\mathrm{C}_{2}{ }^{*}$ chemiluminescence signal within the vertical central plane $(Y=0)$ obtained by computing the average of 200 individual images. Flow is left to right. 


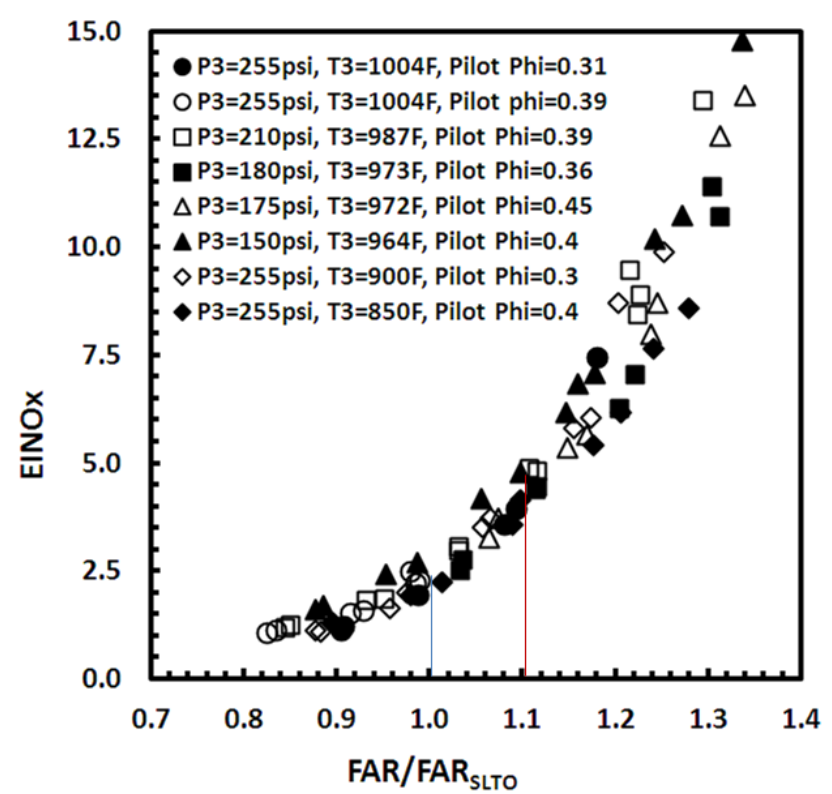

Figure 21.-Measured NOx emissions from the single-injector PICS combustor testing at NASA. For these tests, unheated liquid Jet fuel was supplied to both the main and pilot circuits, and emissions samples were obtained at several different operating conditions, including variations in inlet temperature, pressure, and fuel/air ratio. Emissions are plotted against FAR in the combustor, as calculated from total fuel flow and combustor airflow, normalized by the FAR at sea-leveltakeoff (SLTO) for this engine cycle. FAR/FAR SLTO $^{=}$ 1.10 at supersonic cruise, as indicated by the red lines. The blue lines indicate the FAR/FAR SLTO $=1.0$ sealevel-takeoff condition.

An improved estimate of supersonic cruise EINOx can be obtained from the correlation developed by NASA under the Advanced Subsonic Technology (AST) Program, for various fuel-lean aircraft

combustor configurations (Refs. 29 and 30). In this correlation, EINOx scales with inlet pressure as $\mathrm{P}^{0.595}$ (roughly square-root of $\mathrm{P}$ ) and inlet temperature as $\exp (\Delta \mathrm{T} 3 / 194 \mathrm{~K})$, or $\exp (\Delta \mathrm{T} 3 / 350 \mathrm{R})$ in English units. Using this correlation, EINOx data from 175 to 180 psia are shown in Figure 22(a) after scaling to the supersonic cruise combustor inlet temperature of $1087^{\circ} \mathrm{F}$. The scaled data show an EINOx value of about 6 at $\mathrm{FAR} / \mathrm{FAR}_{\mathrm{SLTO}}=1.1$ for supersonic cruise. We note, however, that in the NASA rig the combustor residence time was significantly longer than expected in an actual engine application, as a result of the 12-in. distance between the PICS injector exit (the combustor dome) and the emissions-probe location. Thus, in an actual engine combustor we expect the liquid-fuel PICS NOx emissions to be well below the 6 EINOx "worst-case" scenario predicted here.

Figure 22(b) plots EINOx values at 850 to $900^{\circ} \mathrm{F}$ inlet temperature, scaled to the 329 psia sea-level-takeoff pressure for this supersonic engine cycle. Thus, at $329 \mathrm{psia}$ and $890^{\circ} \mathrm{F}$ inlet conditions, for sea-level takeoff, the liquid-fuel PICS configuration is predicted to deliver an EINOx value of about 3 (or less, given that the combustor residence time in the NASA rig is longer than expected in an aircraft combustor application). 

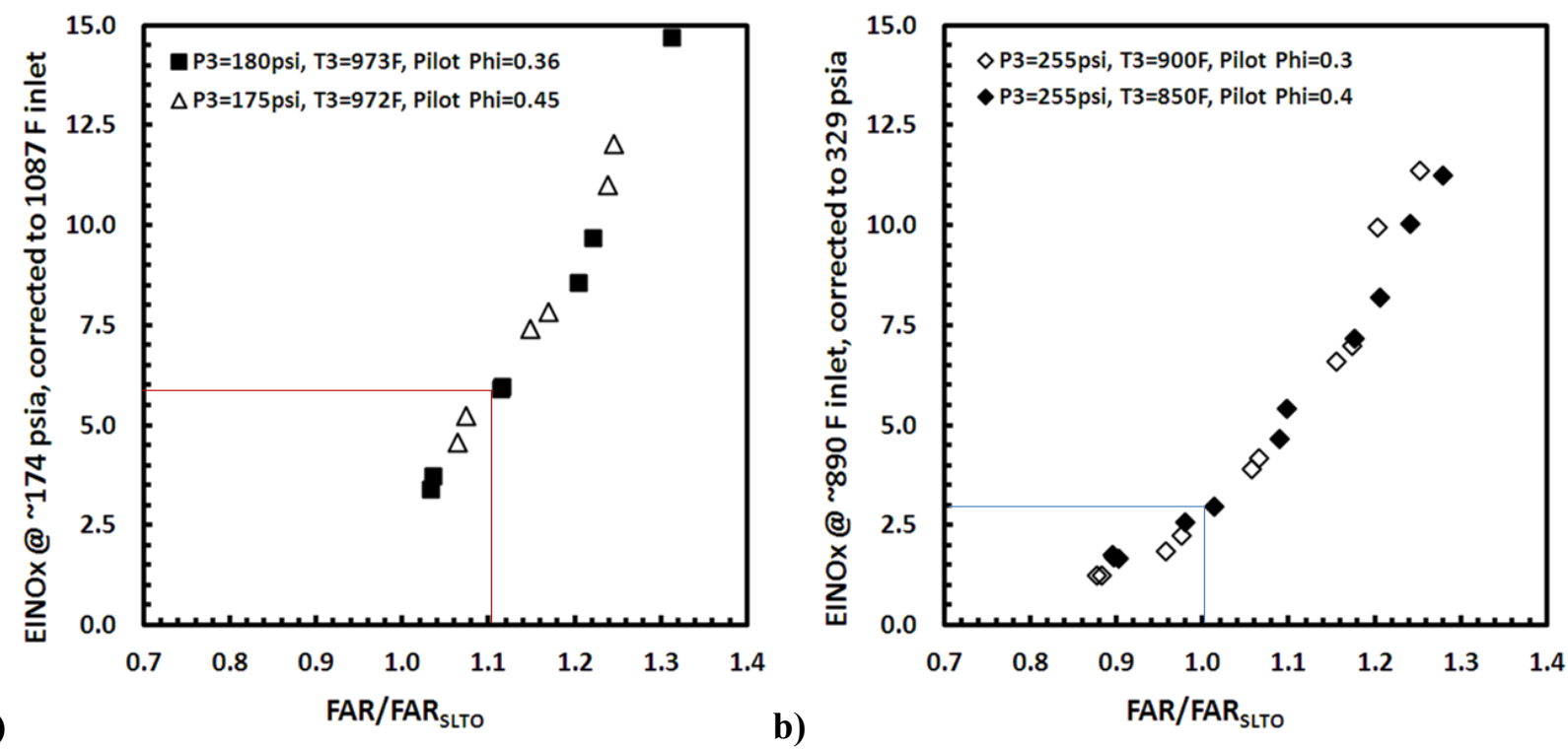

Figure 22.-Predicted NOx emissions from the single-injector PICS combustor testing at NASA, based on scaling the measured results of Figure 21 to cruise conditions (left-hand panel) and sea-level-takeoff conditions (right-handpanel) for the supersonic cycle (Table 1) by applying the NASA correlation (Refs. 29 and 30) for NOx emissions from lean-burn aircraft combustors.

Finally, we note that the FAR values plotted in Figures 21 and 22 are based on a calculated airflow to the combustor. Two calculations are accounted for: First, because some air leaked around the combustor dome in the NASA rig (bypassing the primary combustion zone), and because this air leakage was not constant (it worsened during the course of testing), combustor airflow was calculated from the known effective area of the PICS injector and the measured pressure drop across the injector during testing. Thus, the leakage air (which did not participate in combustion) was ignored. Second, as in the UTRC testing (Ref. 3), the combustor airflow was set 14 percent below the cycle specification (making FAR 14 percent higher than the cycle specification for each power condition) to account for an expected 14 percent liner cooling-air requirement for a full-scale annular PICS combustor in an engine. This essentially corrects for the fact that the NASA flametube rig was ceramic-lined and not air-cooled, and therefore has a lower total air requirement than an engine combustor. We note that reducing the liner cooling-air requirement below 14 percent, such as enabled by new materials or cooling technologies, will improve NOx performance (reduce emissions) by enabling increased process air for leaner combustion. The NOx data in all cases are consistent in being reported without correction to standard humidity, since high-altitude supersonic flight occurs in dry air, and the facilities at both NASA and UTRC supplied dried air to the combustion test rigs.

\section{Conclusion}

We have presented computational and experimental analyses of the UTRC PICS injector, which has potential for application in an engine to meet the Pratt \& Whitney $\mathrm{N}+3$ supersonic cycle, or a subsonic $\mathrm{N}+2$ engine cycle. NASA has defined technology targets for near term (called "N+1", circa 2015), midterm ("N+2", circa 2020) and far term ("N+3", circa 2030) that specify realistic emissions and fuel efficiency goals for commercial aircraft. Experimental methods were also employed for select points of the subsonic cycle engine; cruise, approach, and idle with a slightly elevated inlet pressure. For the supersonic case, a PICS-based combustor was modeled using the National Combustion Code.

Experiments at NASA employed gas analysis and a suite of laser-based measurement techniques to characterize the combustor flow downstream from the PICS dump plane. Gas analysis results showed that at both supersonic and subsonic cruise conditions, EINOx met the target goal of below 5 . 
We saw that for the supersonic cruise point, use of ambient temperature fuel at the de-rated air inlet temperature, did not result in fully vaporized fuel before exiting the main fuel-air mixing passage. Results from the optical techniques compared well with the numerical predictions, and show the fuel-air mixture is not uniform, which is to be expected because the fuel was injected at room temperature. Analysis of fuel PLIF and PLS results indicate that the liquid fuel is evaporated an axial distance approximately 60 percent of the distance it takes the total remaining fuel to be consumed. Overall, the results show potential for meeting NASA's supersonic cruise emissions goals with liquid fuel in all circuits.

The subsonic cruise point performed well for emissions, with EINOX $<5$. For this point we determined, that at most 10 percent of the total fuel signal was from the liquid. The higher inlet temperature and pressure, along with the commensurate higher flow rates and lower FAR contributed to a higher vaporization rate and better mixing, which is reflected in the more uniform fuel distribution compared to that for the supersonic cruise condition.

For the approach points, PLIF and PLS results show that Approach-2 with fuel staging between pilot an main is better mixed than Approach-1 which uses pilot only and that it produced lower NOx emissions. Analysis of the Approach-1 case also indicated that the PLS raw signal exceeded the PLIF signal, indicating that the majority of fuel was in the liquid phase.

The idle cases use only the pilot. Results indicated that idle case with the higher FAR exhibits less uniformity in fuel pattern and much more reactivity farther downstream. This also resulted in higher EINOX levels.

Using scaling methods previously developed at NASA, analysis of gas analysis results indicates that, at 329 psia and $890^{\circ} \mathrm{F}$ inlet conditions, for sea-level takeoff, the liquid-fuel PICS configuration is predicted to deliver an EINOx value of about 3 .

\section{References}

1. Lee, D.S., Pitari, G., Grewe, V., Grierens, K., Penner, J.E., Petzold, A., Prather, M.J., Schumann, U., Bais, A., Berntsen, T., Iachetti, D., Lim, L.L., and Sausen, R., Atmospheric Environment, Vol. 44, 2010, pp. 4678-4734.

2. Bulzan, D., "Supersonics Project High Altitude Emissions Overview," 2012 Fundamental Aeronautics Program Technical Conference, 2012.

3. Smith, L.L., Dai, Z., Lee, C., Fotache, C.G., Cohen, J.M., and Hautman, D.J., "Advanced Combustor Concepts for Low Emissions Supersonic Propulsion," Proceedings of ASME Turbo Expo 2012, GT2012-69078, 2012.

4. Stubbs, R.M. and Liu, N.-S., "Preview of the National Combustion Code," AIAA 97-3114, 1997.

5. Quealy, A., Ryder, R., Norris, A., and Liu, N.-S., "National Combustion Code: Parallel Implementation and Performance," NASA/TM-2000-209801, 2000.

6. Quealy, A., "National Combustion Code Parallel Performance Enhancements," NASA/CR_2002211340.

7. Shih, T.-H., Povinelli, L.A., Liu, N.-S., and Chen, K.-H., "Generalized Wall Function for Complex Turbulent Flows," NASA/TM-2000-209936, 2000.

8. Chien, K.Y., "Prediction of Boundary-Layer Flows with a Low-Reynolds-Number Turbulence Model," AIAA Journal, Vol. 20, No. 1, 1982, pp. 33-38.

9. Shih, T.-H., Chen, K.-H., Liu, N.-S., Lumley, J.L., "Modeling of Turbulent Swirling Flows," NASA-TM-113112, 1998.

10. Shih, T.-H., Chen, K.-H., and Liu, N.-S., "A Non-Linear k-epsilon Model for Turbulent Shear Flows," AIAA Paper 98-3983, 1998.

11. Raju, M.S., "LSPRAY-II: A Lagrangian Spray Module,”NASA/CR—2004-212958, 2004.

12. Venkateswaran, S., Weiss, J.M., Merkle, C.L., Choi, Y.-H., "Propulsion-Related Flowfields Using Preconditioned Navier-Stokes Equations," AIAA-92-3437, 1992.

13. Venkateswaran, S., Merkle, C.L., "Efficiency and Accuracy Issues in Contemporary CFD Algorithms," AIAA-2002-2251, 2002. 
14. Chen, K.-H., Norris, A.T., Quealy, A., and Liu, N.-S., "Benchmark Test Cases for The National Combustion Code," AIAA Paper 98-3855, 1998.

15. Iannetti, A., Tacina, R., Jeng, S.-M., and Cai, J., "Towards Accurate Prediction of Turbulent, ThreeDimensional, Recirculating Flows With the NCC," NASA/TM-2001-210761, AIAA-2001-0809, 2001.

16. Shih, T.-H., Norris, A., Iannetti, A., Marek, C.J., Smith, T.D., Liu, N.-S., and Povinelli, L.A., "A Study of Hydrogen/Air Combustor Using NCC," AIAA-2001-808, 2001.

17. Iannetti, A.C., Chen, K.-H., "An Initial Comparison of National Combustor Code Simulations Using Various Chemistry Modules With Experimental Gas Turbine Combustor Data," AIAA-2000-0330, 2000 .

18. NX, formerly Unigraphics NX, http://www.plm.automation.siemens.com/en_us/products/nx/.

19. Cubit, https://cubit.sandia.gov/, Sandia National Labs, Albuquerque, NM, USA.

20. Pointwise, http://www.pointwise.com/pw/, Pointwise, Inc., Fort Worth, TX, USA.

21. Westbrook, C.K. and Dryer, F.L., "Simplified Reaction Mechanisms For The Oxidation Of Hydrocarbon Fuels In Flames,” Combust. Sci. Technology, Vol. 27, 1981, p. 31.

22. Ajmani, K., Kundu, K., and Penko, P., "A Study on Detonation of Jet-A Using a Reduced Mechanism,” AIAA-2010-1515, 2010.

23. Zeldovich, Y.B. "The Oxidation of Nitrogen in Combustion and Explosions," Acta Physicochimica URSS, Vol.21, 1946, pp. 577-628.

24. Fennimore, C.P., 13th Symposium (Int) on Combustion, 1971, p. 371.

25. Amsden, A.A., O'Rourke, P.J., and Butler, T.D., "KIVA-II: A computer program for chemically reactive flows with sprays," Report Number LA-11560-MS, Los Alamos National Lab, 1989.

26. Lefebvre, A.H., Atomization and Sprays, Hemisphere Publishing Corporation, New York, 1989.

27. El Banhawy, Y. and Whitelaw, J.H., "Calculation of the Flow Properties of a Confined KeroseneSpray Flame," AIAA Journal, Vol. 18, No. 12, 1980, pp. 1503-1510.

28. Swanson, R.C., and Turkel, E., "Multistage Schemes with Multigrid for Euler and Navier-Stokes Equations," NASA-TP-3631, 1997.

29. Tacina, R., Wey, C., and Choi, K., 2001, "Flame Tube NOx Emissions Using a Lean-Direct-WallInjection Combustor Concept," NASA Technical Memorandum no. NASA/TM-2001-211105 and AIAA Paper AIAA-2001-3271, 2011.

30. Tacina, R., Wey, C., Laing, P., and Mansour, A., "A Low NOx Lean-Direct Injection, Multipoint Integrated Module Combustor Concept for Advanced Aircraft Gas Turbines," NASA/TM-2002$211347,2002$. 


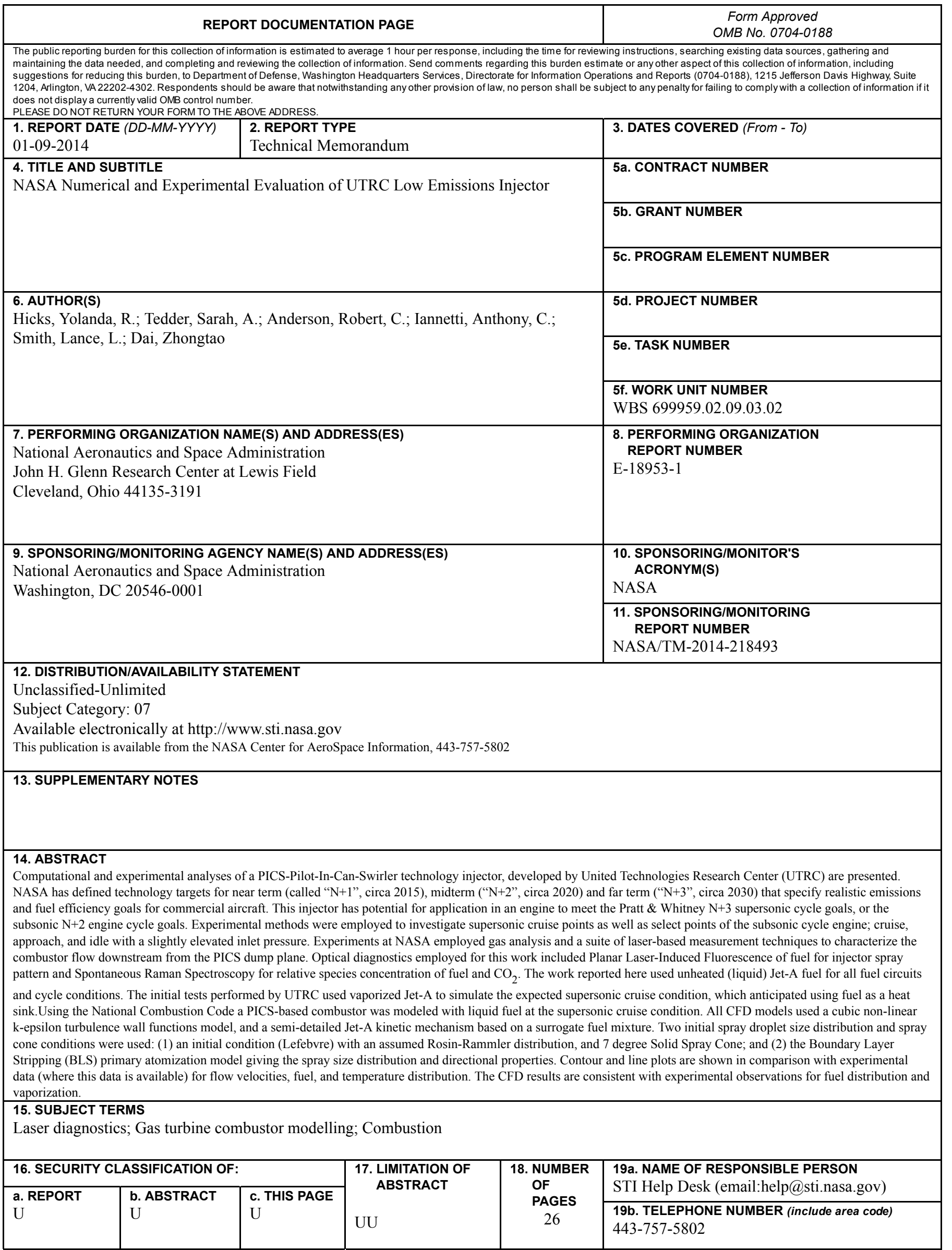



